\title{
Green supply chain considering product re-production rate
}

\author{
Chui-Yu Chiu, ${ }^{*}$, Ting-Ying Wu, Jia-Fang Li, Catur P Hary \\ Department of Industrial Engineering and Management, National Taipei University of Technology \\ 1, Sec. 3, Zhongxiao E. Rd., Taipei 10608 Taiwan \\ *Corresponding Author: cychiu@mail.ntut.edu.tw
}

\begin{abstract}
This study incorporates the concept of a green supply chain into corporate operational goals to reduce resource waste. Therefore, based on this concept, this paper proposes a green-closed supply chain integration operation model, and integrates the manufacturing supply chain and the reverse logistics chain to form a closed supply chain, that is, the reverse supply chain for recycling used products is the same path as the manufacturing supply chain; The reverse chain is mainly to recycle the second-hand products of customers and re-manufacture, and also consider the quality of second-hand products to explore its impact on the entire model.

In the post-adjusted model of the second-hand raw material re-production rate $(\mathrm{k})$, the sensitivity analysis of the impact of government subsidies and second-hand product recovery rate on net income is analyzed, and it is known that when government subsidies increase, the net income of the supply chain will increase accordingly, and when the recovery rate of second-hand products increases, its net income will also increase.
\end{abstract}

Keywords: product re-production rate, green supply chain management, closed supply chain

\section{Introduction}

With the rapid development of science and technology and the continuous development of the economy, the environmental pollution problem has gradually increased. Therefore, the government has also proposed many response policies and gradually developed into environmental protection concepts in the supply chain. Governments in many foreign countries have regulations in place to regulate and restrict companies, such as European governments implementing environmental-related laws to ensure that their environment can be managed and developed sustainably, and that humans in the future can take from nature and give back to nature. To create an ecological environment for recycling. Therefore, this study hopes to establish a green supply chain system and recycle the used products to reduce waste of resources and bring more profits to the company.

\section{Literature review}

\subsection{Green supply chain management}

With the rise of environmental awareness in the past decade, more and more experts and scholars believe that waste generated or discarded in the manufacturing process should be reduced, or useful waste should be recycled to achieve green supply chain management. (GSCM) concept.

Ashley (1993) proposes that intelligent planning and design can effectively reduce environmental pollution. This is the best way to protect the environment. Therefore, when designing new products, the environmental protection features will be added, including detachability, recyclability, maintainability, rework ability, and reusability, they are all considered as environmental design goals. Narasimhan and Carter (1998) Government and business face the pressure of global environmental protection such as reducing environmental pollution, reducing waste generation and using green materials. Therefore, in order to solve this problem, many companies will adopt the concept of supply chain management and environmental protection. The combination has produced a green supply chain management 
method, and also has achieved balanced development in environmental awareness and business operations. Sarkis (2003) incorporates environmental factors into the supply chain and constructs a model that facilitates management decisions with the goal of developing a comprehensive green supply chain system. Zhu and Sarkis (2004) Green Supply Chain Management (GSCM) is an important way for companies to improve their performance. In the manufacturing process, not only environmental issues need to be considered, but also productivity and profit also need to be considered. In addition, the green supply chain is also targeted at the green procurement in the integrated supply chain, including suppliers, manufacturers, customers, and reverse supply chains. Sheu et al. (2005) proposed an optimized green supply chain model and applied the model of multi-objective planning to the reverse supply chain operation of integrated logistics and second-hand product recycling. The results of the study showed that compared with the existing operational performance. In other words, its total net profit can be increased by $21.1 \%$. Lin (2013) proposed that Green Supply Chain Management (GSCM) is a way to improve environmental performance, and companies should strengthen GSCM practices, including green procurement, green design, and product recycling, to improve economic performance.

\subsection{Closed supply chain}

The Closed Loop Supply Chains (CLSC) is a new logistics concept proposed in 2003. The goal is to perform closed treatments on flowing materials to reduce emissions of pollutants and waste, and to manufacture them at lower cost.

The products recovered by Guide. Jr. and Wassenhove (2009) are able to obtain a certain profit in the reverse supply chain. Akçali and Çetinkaya (2010) propose that a closed supply chain (CLSC) can help companies improve operational capabilities and economic viability. Jighyasu et al. (2017) suggest that a closed supply chain should focus on recycling products from the customer side, re-manufacturing them, and finally market it. Rabindranath et al. (2018) proposed a nonlinear model with the aim of maximizing profit, which includes re-product profit. In the process of remanufacturing in a closed supply chain, the manufacturer recycles the customer's second-hand goods, disassembles, repairs or remanufactures, and finally sells them with new products. In addition, purchase costs and remanufacturing costs are incurred in the reverse supply chain for the acquisition of used products.
The Green Closed Loop Supply Chains (GCLSC) is an extension of the closed supply chain, and incorporates the concept of environmental protection into the supply chain, including green design, green manufacturing, etc., recycling of materials and used products. To reduce its level of environmental pollution and impact. Anurag et al. (2016) added the concept of a green supply chain to a closed supply chain to reduce waste of resources by recycling electronic components and to maximize profits and minimize carbon footprint.

\section{Research methodology}

In this chapter, the manufacturing supply chain and the reverse supply chain will be integrated and the maximum profit of the model will be solved through linear programming. The model proposed by Sheu et al. (2005) uses multi-objective programming to improve the logistics operation of green supply chain systems, and its goal is to maximize profits in the general manufacturing chain and reverse logistics chain. In addition, this study improved its operation in the reverse supply chain of recycled products, and merged the collection plant and the dismantling plant into retailers and wholesalers.

\subsection{Symbols and assumptions}

The following table 3.1 shows the symbolic description of the basic model

Table 3.1 Symbol and description of the basic model

\begin{tabular}{l|l}
\hline $\mathrm{Cost}$ & \\
\hline $\mathrm{Cr}$ & Raw material unit cost \\
\hline $\mathrm{Cp}$ & Purchasing unit cost in the supply chain \\
\hline $\mathrm{Cm}$ & Manufacturing cost of all manufactured goods \\
\hline $\mathrm{Cre}$ & Rework cost of defective products \\
\hline $\mathrm{Cir}$ & Storage cost of raw materials \\
\hline $\mathrm{Ci}$ & Inventory cost of the product \\
\hline $\mathrm{Cint}$ & $\begin{array}{l}\text { Recovering the cost of storage of unprocessed used } \\
\text { products by members of the supply chain }\end{array}$ \\
\hline $\mathrm{Cit}$ & $\begin{array}{l}\text { Recovering the cost of storage of processed second- } \\
\text { hand products by members of the supply chain }\end{array}$ \\
\hline $\mathrm{Ct}$ & Transportation cost \\
\hline $\mathrm{Cc}$ & $\begin{array}{l}\text { Collection cost of second-hand products for } \\
\text { terminal customers }\end{array}$ \\
\hline $\mathrm{Cl}$ & Labor cost \\
\hline $\mathrm{Ctr}$ & Processing cost \\
\hline $\mathrm{Cf}$ & Final processing unit cost \\
\hline $\mathrm{Ci}, \mathrm{j}$ & Cost from the i-th layer to the $\mathrm{j}$-th layer in the \\
\hline
\end{tabular}




\begin{tabular}{l|l}
\hline & forward or reverse supply chain \\
\hline Revenue \\
\hline Ri,j & $\begin{array}{l}\text { Unit revenue from the i-th layer to the j-th floor in } \\
\text { the forward or reverse supply chain }\end{array}$ \\
\hline $\mathrm{S}$ & Unit subsidy provided by the government \\
\hline Quantity \\
\hline Qr & Quantity of raw materials \\
\hline Qp & Purchase quantity \\
\hline Qm & Manufacturing quantity \\
\hline Qre & $\begin{array}{l}\text { The number of products that can be reworked by the } \\
\text { wholesaler }\end{array}$ \\
\hline Qir & Inventories of raw materials \\
\hline Qi & Inventory quantity of products \\
\hline Qint & Recycling of unprocessed used stocks by supply \\
\hline $\mathrm{t}$ & chain members \\
\hline Qit & Recycling the quantity of processed second-hand \\
\hline products by supply chain members
\end{tabular}

The following are assumptions about the basic model, and this paper will construct mathematical models based on the following assumptions.
(a) The product demand of the end customer is known and constant.
(b) Consider only a single product in the model.
(c) Not allowed out of stock.
(d) Facility capacity and inventory capacity are known and constant.
(e) Know the rework rate of used products. That is, the proportion of second-hand products that can be reworked in the dismantling factory (wholesaler).
(f) Known second-hand product recovery rate. This is

the ratio of the number of second-hand products that are recovered by the end customer.

(g) Known production defect rate. This is the proportion of product defects in the manufacturer's production process.

(h) The conversion rate of raw materials and products is known. That is, the amount of raw materials that a unit of second-hand products can decompose.

(i) The time range is unlimited.

\subsection{Model}

This study integrates the manufacturing chain and the reverse chain in the supply chain to form a closed supply chain, that is, the reverse supply chain of used products is in the same path as the manufacturing chain, and obtains its maximum net profit.

\subsubsection{Objective function}

The objective function is constructed by hypotheses and symbols, and the maximum profit of the supply chain is solved by the function. It is known from Figure 3.1 that the manufacturing supply chain is supplied by the raw material supplier to the manufacturer and sold to the customer; while the reverse supply chain is from the customer to the collection plant and the dismantling plant, and finally back to the manufacturer. Re-reproduction. In the dismantling plant, if the recycled second-hand product can be reused repeatedly, the second-hand product is dismantled and recycled to the manufacturer; if it is not recyclable, the second-hand product is sent to the final disposal site for disposal.

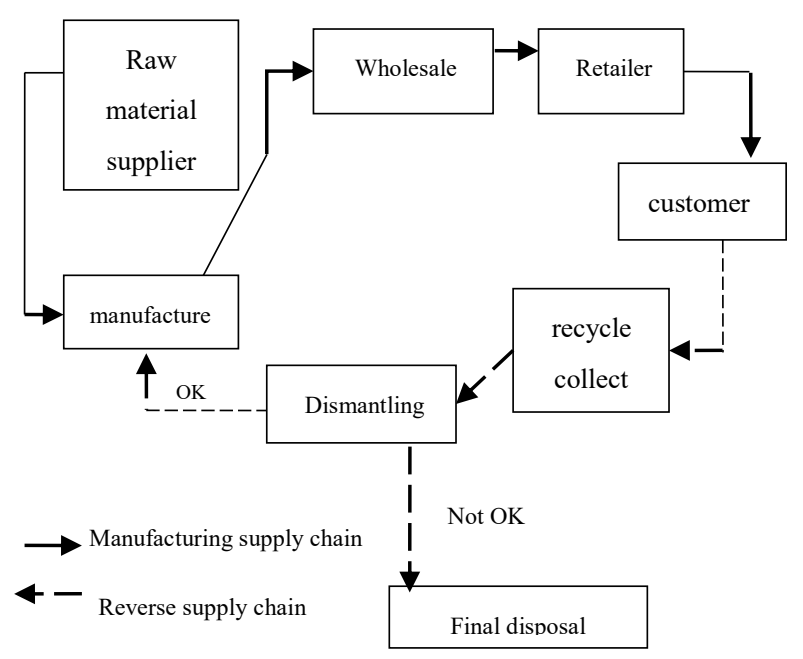

Fig. 3.1. Basic model flow chart

The following table3.2 shows the supply chain related 
symbols. This study integrates the manufacturing supply chain with the reverse supply chain. The objective function of this model is net profit (NP) = total return (AR) - total cost (AC).

Table 3.2 Function initial meaning

\begin{tabular}{l|l}
\hline $\begin{array}{l}\text { AR } \\
\text { (Aggregate Revenues) }\end{array}$ & Total revenue \\
\hline $\begin{array}{l}\text { AC } \\
\text { (Aggregate Cost) }\end{array}$ & Total cost \\
\hline $\begin{array}{l}\text { NP } \\
\text { (Net Profit) }\end{array}$ & Net profit \\
\hline $\begin{array}{l}\text { MR } \\
\text { Ranufacturing chain }\end{array}$ & $\begin{array}{l}\text { Manufacturing supply } \\
\text { chain revenue }\end{array}$ \\
\hline $\begin{array}{l}\text { RR } \\
\text { (Reverse chain Revenues) }\end{array}$ & $\begin{array}{l}\text { Reverse supply chain } \\
\text { revenue }\end{array}$ \\
\hline $\begin{array}{l}\text { RS } \\
\text { (Reverse chain Subsidies) }\end{array}$ & Government subsidies \\
\hline $\begin{array}{l}\text { APC } \\
\text { (Aggregate Procurement Cost) }\end{array}$ & Total purchase cost \\
\hline $\begin{array}{l}\text { AMC } \\
\text { (Aggregate Manufacturing } \\
\text { Cost) }\end{array}$ & Total manufacturing cost \\
\hline $\begin{array}{l}\text { AIC } \\
\text { (Aggregate Inventory Cost) }\end{array}$ & Total inventory cost \\
\hline $\begin{array}{l}\text { ATC } \\
\text { (Aggregate Transportation } \\
\text { Cost) }\end{array}$ & Total transportation cost \\
\hline ACC & Total processing cost of \\
\hline ALC
\end{tabular}

$\operatorname{Max} \mathrm{NP}=\mathrm{AR}-\mathrm{AC}=(\mathrm{MR}+\mathrm{RR}+\mathrm{RS})-(\mathrm{APC}+$

$\mathrm{AMC}+\mathrm{AIC}+\mathrm{ATC}+\mathrm{ACC}+\mathrm{ALC}+\mathrm{AFC}+\mathrm{ATTC})$

\subsubsection{Income and cost}

In this subsection, equation (3.2) is the model of income, and equation (3.3) to (3.10) are the cost models. In the supply chain, the cost items include procurement cost, manufacturing cost, inventory cost, transportation cost, rework cost, and labor cost. The final disposal cost of second-hand products and the disposal cost of second-hand products.

AR: Total revenue. Includes revenue from manufacturing supply chains and reverse supply chains, as well as government subsidized income. The subsidies are for collection factories and dismantling factories.

$$
\begin{gathered}
A R=M R+R R+R S \\
=\sum_{\forall t}\left\{\begin{array}{c}
{\left[\sum_{i=1}^{4} R_{i, \mathrm{i}+1}(t) * Q_{i, \mathrm{i}+1}(t)\right]+} \\
{\left[\sum_{i=3}^{5} R_{i, \mathrm{i}-1}(t) * Q_{i, \mathrm{i}-1}(t)\right]+} \\
{\left[\sum_{\forall s 4} \sum_{\forall s 3} S * \operatorname{Qint}_{43}\right]+} \\
{\left[\sum_{\forall s 3} \sum_{\forall s 2} S * Q_{i n t}\right]}
\end{array}\right\}
\end{gathered}
$$

APC: Total purchase cost. It includes the initial cost of raw materials, the purchase cost of raw materials, the purchase cost of second-hand materials after dismantling, and the cost of purchasing products.

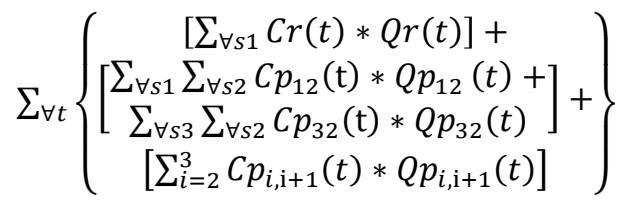

AMC: Total manufacturing costs. Including manufacturing costs and rework costs.

$$
\sum_{\forall t}\left\{\begin{array}{c}
{\left[\sum_{\forall s 2} \operatorname{Cm}(t) * \operatorname{Qm}(t)\right]+} \\
{\left[\sum_{\forall s 2} \operatorname{Cre}(t) * \operatorname{Qre}(t)\right]}
\end{array}\right\}
$$

AIC: Total inventory cost. Including raw material inventory cost, product inventory cost, storage cost of recycling unprocessed used products, and processed storage cost of used materials.

$$
\sum_{\forall t}\left\{\begin{array}{c}
{\left[\sum_{i=1}^{2} \sum_{\forall s i} \operatorname{Cir}(t) * \operatorname{Qir}(t)\right]+} \\
{\left[\sum_{i=2}^{4} \sum_{\forall s i} \operatorname{Ci}(t) * \operatorname{Qi}(t)\right]+} \\
{\left[\sum_{i=3}^{6} \quad i \neq 5 \sum_{\forall s i} \operatorname{Cint}(t) * \operatorname{Qint}(t)\right]+} \\
{\left[\sum_{i=2}^{3} \sum_{\forall s i} \operatorname{Cit}(t) * \operatorname{Qit}(t)\right]}
\end{array}\right\}
$$

ATC: Total transportation costs. It includes transportation costs for the manufacturing supply chain, transportation costs for the reverse supply chain, and transportation costs for the dismantling of the plant to the final disposal site.

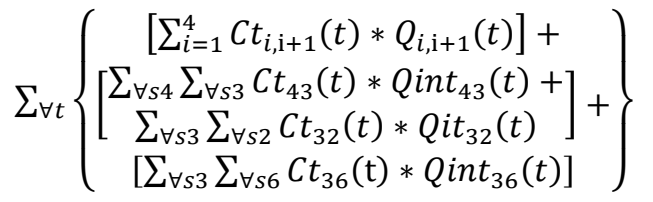

ACC: Total collection cost. That is, recycling used products 
from customers to collection factories.

$$
\sum_{\forall t}\left\{\sum_{\forall s 5} \sum_{\forall s 4} C c_{54}(t) * \operatorname{Qint}_{54}(t) * \beta\right\}
$$

ALC: Total labor costs. That is, the labor costs of all levels.

$$
\sum_{\forall t}\left\{\sum_{i=1}^{6} \sum_{\forall s i} C l(t) * Q l(t)\right\}
$$

AFC: Total cost of final disposal of used products. That is, the final disposal of all used products.

$$
\sum_{\forall t}\left\{\sum_{\forall s 6} C f(t) * Q f(t)\right\}
$$

ATTC: Total processing cost of used products. That is, the processing cost of all used products in the reverse supply chain, except for the final disposal.

$$
\sum_{\forall t}\left\{\sum_{i=2}^{4} \sum_{\forall s i} \operatorname{Ctr}(t) * Q \operatorname{tr}(t)\right\}
$$

\subsubsection{Restricted method}

Restrictions include demand restricted, inventory restricted, and resource return restrictions. The stock limit type includes the quantity of stock, the quantity of products and the quantity of second-hand products recovered, and is designed according to the facilities capacity of each class, which are raw material suppliers, product manufacturers, wholesalers, retailers and final disposal sites.

(1) Demand restricted:

$$
D(t) \geq \sum_{\forall s 4} \sum_{\forall s 5} Q i_{45}(t) \geq 0, \forall t
$$

(2) Inventory restricted:

a) Raw material supplier

$$
\begin{array}{r}
0 \leq Q i r_{1}(\mathrm{t})=Q i r_{1}(t-1)+Q r_{1}(t)- \\
\sum_{\forall s 1} \sum_{\forall s 2} \operatorname{Qir}_{12}(t) \leq \operatorname{Sir}_{1}, \forall\left(s_{1}, t\right)
\end{array}
$$

b) Raw material supplier

- Raw materials

$$
0 \leq \operatorname{Qir}_{2}(\mathrm{t})=\operatorname{Qir}_{2}(t-1)+
$$

$\left[\sum_{\forall s 1} \sum_{\forall s 2} Q r_{12}(t)+\sum_{\forall s 3} \sum_{\forall s 2} Q r_{32}(t)\right]-\gamma * Q m(t) \leq$

$$
\mathrm{Sir}_{2}, \forall\left(s_{2}, t\right)
$$

- $\quad$ Product

$$
\begin{array}{r}
0 \leq Q i_{2}(\mathrm{t})=Q i_{2}(t-1)+Q \mathrm{~m}(\mathrm{t})- \\
\sum_{\forall s 2} \sum_{\forall s 3} Q i_{23}(t) \leq S i_{2}, \forall\left(s_{2}, t\right)
\end{array}
$$

c) Wholesalers and dismantling factories

- Product

$$
\begin{gathered}
0 \leq Q i_{3}(\mathrm{t})=Q i_{3}(t-1)+\sum_{\forall s 2} \sum_{\forall s 3} Q i_{23}(t)- \\
\sum_{\forall s 3} \sum_{\forall s 4} Q i_{34}(t) \leq S i_{3}, \forall\left(s_{3}, t\right)
\end{gathered}
$$

- $\quad$ Recycled used products

$0 \leq \operatorname{Qint}_{3}(\mathrm{t})=\operatorname{Qint}_{3}(t-1)+\sum_{\forall s 4} \sum_{\forall s 3} \operatorname{Qint}_{43}(t)-$

$$
\sum_{\forall s 3} \sum_{\forall s 6} \operatorname{Qint}_{36}(t) \leq \operatorname{Sint}_{3}, \forall\left(s_{3}, t\right)
$$

- Materials after dismantling of used products

$$
\begin{gathered}
0 \leq \operatorname{Qit}_{3}(\mathrm{t})=\operatorname{Qit}_{3}(t-1)+\alpha * \operatorname{Qint}_{43}(\mathrm{t})- \\
\sum_{\forall s 3} \sum_{\forall s 2} Q_{i t_{32}}(t) \leq \operatorname{Sit}_{3}, \forall\left(s_{3}, t\right)
\end{gathered}
$$

d) Retailer and collection factory

- Product

$$
\begin{gathered}
0 \leq Q i_{4}(\mathrm{t})=Q i_{4}(t-1)+\sum_{\forall s 3} \sum_{\forall s 4} Q i_{34}(t)- \\
\sum_{\forall s 4} \sum_{\forall s 5} Q i_{45}(t) \leq S i_{4}, \forall\left(s_{4}, t\right)
\end{gathered}
$$

- $\quad$ Recycled used products

$0 \leq \operatorname{Qint}_{4}(\mathrm{t})=\operatorname{Qint}_{4}(t-1)+\sum_{\forall s 5} \sum_{\forall s 4} \operatorname{Qint}_{54}(t)-$

$$
\sum_{\forall s 4} \sum_{\forall s 3} \operatorname{Qint}_{43}(t) \leq \operatorname{Sint}_{4}, \forall\left(s_{4}, t\right)
$$

e) Final disposal site

$$
\begin{gathered}
0 \leq \operatorname{Qint}_{6}(\mathrm{t})=\operatorname{Qint}_{6}(t-1)+ \\
\sum_{\forall s 3} \sum_{\forall s 6} \operatorname{Qint}_{36}(t)-Q f_{6}(t) \leq \operatorname{Sint}_{6}, \forall\left(s_{6}, t\right)
\end{gathered}
$$

(3) Resource return restriction:

$\operatorname{Qre}(t)=\sum_{\forall s 5} \sum_{\forall s 4} \operatorname{Qint}_{54}(t)=\beta * D(t) \geq 0, \forall t$

\subsection{Parameter setting}

Refer to the parameters of Sheu et al. (2005) for setting and adjusting the parameters to meet the parameter values of this study. Table 3.3 is the parameter estimation of the income, Table 3.4 is the parameter estimation of the cost, Table 3.5 is the facility capacity and inventory capacity, and Table 3.6 Estimate for other parameters. As shown in the following table:

Table 3.3 Unit income estimate

\begin{tabular}{llr}
\hline Class & Parameter & $\begin{array}{r}\text { Unit income (unit: US } \\
\text { dollar) }\end{array}$ \\
\hline 1.Supplier & $\mathrm{R} 12$ & 55 \\
\hline 2.Manufacturer & $\mathrm{R} 23$ & 610 \\
\hline \multirow{2}{*}{ 3.Wholwsaler } & $\mathrm{R} 34$ & 825 \\
\cline { 2 - 3 } & $\mathrm{R} 32$ & 30 \\
\hline \multirow{2}{*}{ 4.Retailer } & $\mathrm{R} 45$ & 1,023 \\
\hline 5.Customer & $\mathrm{R} 43$ & 6.8 \\
\hline
\end{tabular}

Table 3.4 Unit cost estimate 


\begin{tabular}{|c|c|c|}
\hline \multirow{3}{*}{ 1.Supplier } & $\mathrm{Cr}$ & 12 \\
\hline & Cir1 & 1.5 \\
\hline & $\mathrm{Cl1}$ & 5 \\
\hline \multirow{11}{*}{ 2.Manufacturer } & Cir2 & 30 \\
\hline & $\mathrm{Ci} 2$ & 42 \\
\hline & Cit2 & 1 \\
\hline & $\mathrm{Cm}$ & 68 \\
\hline & Ctr2 & 1.5 \\
\hline & $\mathrm{Cl} 2$ & 5 \\
\hline & Cre2 & 85 \\
\hline & Cp12 & 13 \\
\hline & $\mathrm{Cp} 32$ & 15 \\
\hline & Ct12 & 0.1 \\
\hline & $\mathrm{Ct} 32$ & 0.1 \\
\hline \multirow{9}{*}{ 3.Wholesaler } & Ci3 & 52 \\
\hline & Cit3 & 1.1 \\
\hline & Cint3 & 0.3 \\
\hline & $\mathrm{Ctr} 3$ & 1.3 \\
\hline & $\mathrm{Cl} 3$ & 8.5 \\
\hline & Cp23 & 409 \\
\hline & $\mathrm{Ct} 23$ & 0.1 \\
\hline & $\mathrm{Ct} 43$ & 0.1 \\
\hline & $\mathrm{Ct} 36$ & 0.06 \\
\hline \multirow{7}{*}{ 4.Retailer } & $\mathrm{Ci} 4$ & 65 \\
\hline & Cint4 & 0.3 \\
\hline & $\mathrm{Ctr} 4$ & 0.3 \\
\hline & $\mathrm{Cl} 4$ & 8.5 \\
\hline & Cp34 & 518 \\
\hline & $\mathrm{Ct} 34$ & 0.1 \\
\hline & Cc54 & 0.6 \\
\hline \multirow{2}{*}{ 5.Customer } & $\mathrm{Cl} 5$ & 8.5 \\
\hline & $\mathrm{Ct} 45$ & 0.25 \\
\hline \multirow{3}{*}{ 6.Final disposal } & Cint6 & 0.06 \\
\hline & $\mathrm{Cl} 6$ & 3.5 \\
\hline & Cf6 & 0.09 \\
\hline
\end{tabular}

Table 3.6 Other parameters

\begin{tabular}{ll}
\hline Parameters & Value \\
\hline Demand from final customers $(\mathrm{D})$ & 6,151 \\
\hline Unit subsidy $(\mathrm{S})$ & 8.7 \\
\hline Second-hand product rework rate $(\alpha)$ & 0.2 \\
\hline Second-hand product recovery rate $(\beta)$ & 0.25 \\
\hline Conversion rate of raw materials and & 1 \\
products $(\gamma)$ & \\
\hline Production defect rate $(\delta)$ & 0.1 \\
\hline
\end{tabular}

\section{Case introduction}

Since the main source of core components is the new raw materials and re-products market, the quality of products manufactured with core components will vary depending on the age of the components recovered in the market. Therefore, the concept of the difference in quality of used raw materials is added to the model. And explore the changes in net income between the adjusted model and the basic model.

The model assumptions, symbols, revenue, cost, and the restriction of the adjusted model, are the same as the basic model.

\section{1 $\quad$ Adjusted model}

In the manufacturing cost of the basic model (AMC), the "Second-hand raw material remanufacturing rate $(\mathrm{k})$ " is added, That means the second-hand raw materials purchased by the manufacturer from the dismantling factory, After judging the quality of the Rework able product.

$$
\sum_{\forall t}\left\{\left[\begin{array}{c}
\mathrm{Cm}(t) * \\
\sum_{\forall s 2}\left[\mathrm{Qm}(t)-(1-k) * Q i t_{32}(t)\right] \\
{\left[\sum_{\forall s 2} \operatorname{Cre}(t) * \operatorname{Qre}(t)\right]}
\end{array}\right\}\right.
$$

\subsection{Sensitivity analysis}

\subsubsection{Compare the net income of the two models}

Table 3.5 Facility capacity and inventory capacity

\begin{tabular}{llr}
\hline & Parameter & Value \\
\hline \multirow{4}{*}{ Facility capacity } & Sir1 & 7,000 \\
\cline { 2 - 3 } & Sir2 & 5,000 \\
\cline { 2 - 3 } & Sint3 & 2,500 \\
\cline { 2 - 3 } & Sint4 & 1,000 \\
\cline { 2 - 3 } & Sint6 & 500 \\
\cline { 2 - 3 } Inventory capacity & Sit3 & Si2 \\
\cline { 2 - 3 } & Si3 & 5000 \\
\hline
\end{tabular}

Net income of the basic model vS Net income of the adjusted model

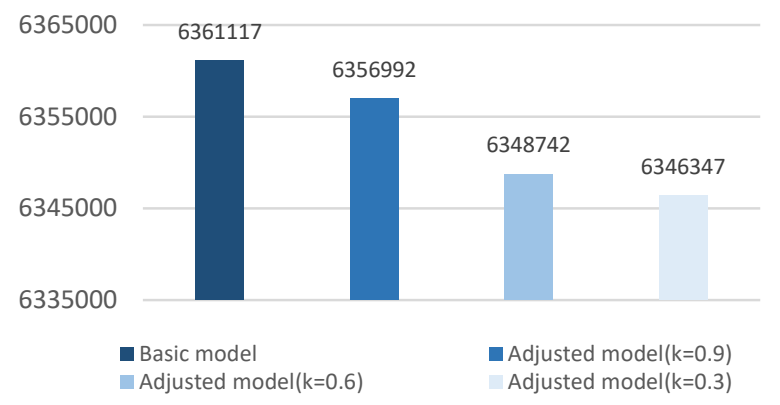


Fig. 4.2. Net income graph of the basic model and the adjusted model

From the net benefit comparison table of the two models in Table 4.1, the maximum net profit value of the supply chain in the basic model is US\$6,361,117, while in the adjusted model (when the second-hand raw material reproducibility rate is $\mathrm{k}=0.9$ ), the maximum net profit value of the supply chain is US\$6,356,992. In addition, when the second-hand raw material reproducibility rate is $\mathrm{k}=0.6$, the maximum net profit value is $6,348,742$ US dollars, and when the second-hand raw material reproducibility rate is $\mathrm{k}=0.3$, the maximum net profit value is $6,346,347$ US dollars. In the reverse supply chain, the quality of the second-hand products recovered will be different, that is, the second-hand materials with poor quality cannot be re-manufactured, which will affect the output of the manufacturers, so the net income in the supply chain will also decrease (see Figure 4.2), so the results of this study can verify the predictions of this study.

\subsubsection{Government subsidies}

In the reverse supply chain, government subsidies are targeted at collection factories (retailers) and dismantling factories (wholesalers). However, this study originally predicted that when the government subsidy is higher, the overall net income will be higher. Figure 4.3 below shows the sensitivity analysis of government subsidies. The results show that the more government subsidies, the more net income.

When the government does not subsidize, the entire supply chain system can obtain a net income of US\$6,358,837 in the basic model; in the adjusted model $(\mathrm{k}=0.9)$, the supply chain system can only generate a net income of US\$6,354,712. The net income of the adjusted model $(\mathrm{k}=0.6)$ was $6,346,462$, and the net benefit of the adjusted model $(\mathrm{k}=0.3)$ was $6,344,067$. In addition, when the government subsidy is $\$ 8.70$, in the basic model, the net income is $\$ 6,361,117$, the adjusted model $(\mathrm{k}=0.9)$ net income is $\$ 6,356,992$, and the adjusted model $(\mathrm{k}=0.6)$ net income is $\$ 6,348,742$ and the adjusted model $(\mathrm{k}=0.3)$ the net income is $\$ 6,346,347$. It can be seen from Figure 4.3 that with the increase of government subsidies, both the subsidy and the net income show a positive slope in any model, and the net income of the supply chain system also has an upward trend.

Table 4.2 Parameter adjustment of government subsidies

\begin{tabular}{|c|c|c|c|c|c|}
\hline \multirow{2}{*}{$\begin{array}{c}\text { Government } \\
\text { subsidy }\end{array}$} & $-10 \%$ & $-5 \%$ & Ref & $+5 \%$ & $+10 \%$ \\
\cline { 2 - 6 } & 7.83 & 8.265 & 8.7 & 9.135 & 9.57 \\
\hline
\end{tabular}

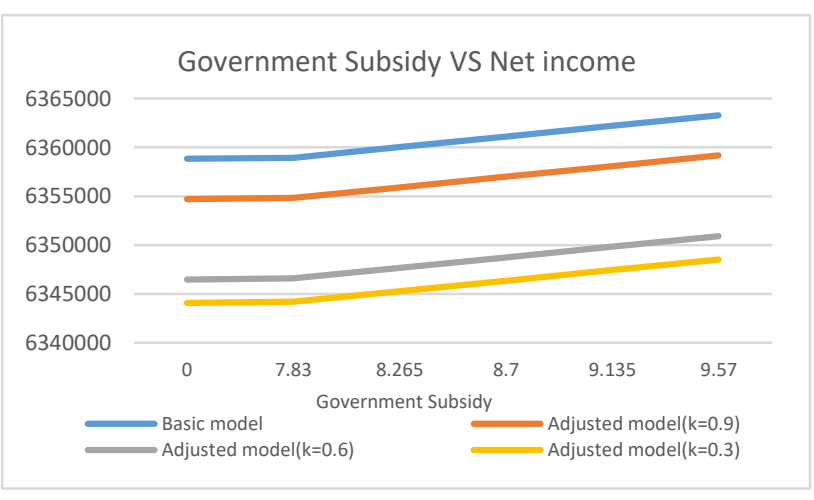

Fig. 4.3. Sensitivity analysis chart of government subsidies

\subsubsection{Second-hand product recovery rate}

The recovery rate of second-hand products refers to the proportion of products recovered from the customer to the collection factory. The sensitivity analysis of the recovery rate of used products in Figure 4.4 shows that the net income of the basic model is greater than the net income of the adjusted model, and when the recovery rate increasing, the overall net income in the supply chain is gradually increasing, therefore consistent with the predictions of this study. When the second-hand product recovery rate is 0 , it means that the second-hand products are not recycled in the supply chain system, so the government has not given the recycling subsidy. The net income of the basic model is US\$6,358,375, the net income of the adjusted model $(\mathrm{k}=0.9)$ is US $\$ 6,354,250$, the net income of the adjusted model $(\mathrm{k}=0.6)$ is US\$6,346,000, and the net income of the adjusted model $(\mathrm{k}=0.3)$ is $\$ 6,343,605$.

Then compare and analyze the two models for different recovery rates. When the recovery rate of used products increases, the overall net income of the supply chain will gradually increase. Therefore, we can know that the relationship between the recovery rate of used products and the net income is positive slope.

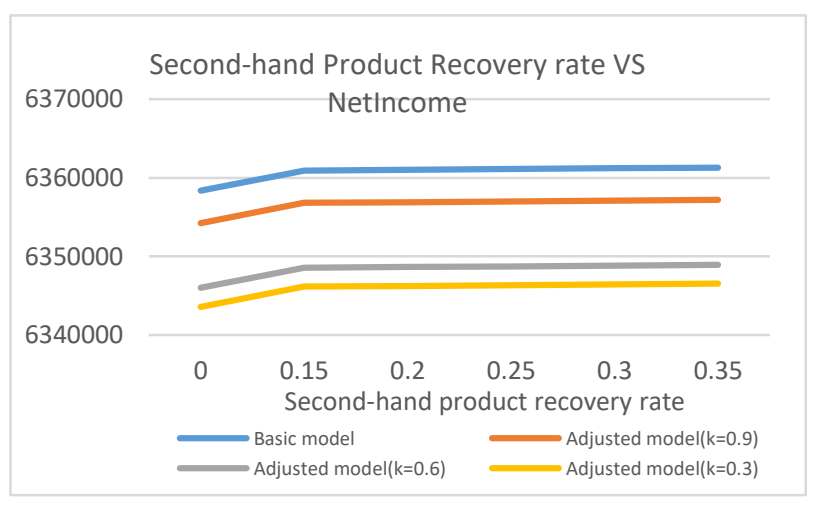


Fig. 4.4. Sensitivity analysis of second-hand product recovery rate

\section{Conclusions}

Due to the rising awareness of environmental protection in the society, many products are designed to be recycled and reused to reduce the harm of waste products to the natural environment, to achieve sustainable development and management, and to create an ecological environment for recycling. Based on this concept, this study constructs a green closed supply chain system, and adds the concept of second-hand raw material quality difference to the basic model to explore the maximum net profit, difference between the two models, and to find the key decision factors in the model through parameter adjustment.

After verification, this study believes that if companies can recycle and re-manufacture second-hand products through the supply chain system, they will be able to earn more profits because manufacturers can buy disassembled used components at lower prices. Therefore, in the process of remanufacturing, the cost can be effectively reduced and more net income can be created. In addition, the recycling and reuse of second-hand products fully reflects the environmental protection concept of today's society, and the reuse of second-hand raw materials that are produced by recycling second-hand products can be used to reduce the environmental pollution, also can provide more contributions at the environmental protection level. In addition, the government's subsidy policy to promote the concept of environmental protection aims to encourage companies to think about how to integrate environmental protection concepts into the sustainable development of the green economy.

\section{References}

(1) Akçali, E., and Çetinkaya, S. "Quantitative models for inventory and production planning in closed-loop supply chains" , International Journal of Production Research, vol. 49, pp2373-2407, 2010

(2) 1

(3) Ashley Steven, "Designing for the environment" , Mechanical Engineering, vol. 115, no. 3, pp52-55, 1993

(4) Jighyasu Gaur, Ramesh Subramoniam, Kannan Govindan and Donald Huisingh, "Closed-loop supply chain management: From conceptual to an action oriented framework on core acquisition" , Journal of
Cleaner Production, vol. 167, pp1415-1424, 2017

(5) Jiuh-Biing Sheu, Yi-Hwa Chou, Chun-Chia Hu, “An integrated logistics operational model for green-supply chain management" , Transportation Research Part E: Logistics and Transportation Review, vol. 41, no. 4, pp287-313, 2005

(6) Joseph Sarkis, "A strategic decision framework for green supply chain management”, Journal of Cleaner Production, vol. 11, no. 4, pp397-409, 2003

(7) Narasimhan, R. and Carter, J.R, "Environmental Supply Chain Management. The Center for Advanced Purchasing Studies” , Arizona State University Tempe, AZ, 1998

(8) Qinghua Zhu and Joseph Sarkis, "Relationships between operational practices and performance among early adopters of green supply chain management practices in Chinese manufacturing enterprises" , Journal of Operations Management, vol. 22, no. 3, pp265-289, 2004

(9) Rabindranath Bhattacharya, Arshinder Kaur and R. K. Amit, "Price optimization of multi-stage remanufacturing in a closed loop supply chain" , Journal of Cleaner Production, vol. 186, pp943-962, 2018

(10) Ru-Jen Lin, "Using fuzzy DEMATEL to evaluate the green supply chain management practices" , Journal of Cleaner Production, vol. 40, pp32-39, 2013

(11) Shan-Lin Yang and Yong-Wu Zhou, "Two-echelon supply chain models: Considering duopolistic retailers' different competitive behaviors” , International Journal of Production Economics, vol. 103, no. 1, pp104-116, 2006

(12) V. Daniel R. Guide. Jr. and Luk N. Van Wassenhove, OR FORUM, "The Evolution of Closed-Loop Supply Chain Research”, Operations Research, vol. 57, no. 1, pp.ii-260, 2009

(13) Vildan Özkır and Hüseyin Başlıgil, “Multi-objective optimization of closed-loop supply chains in uncertain environment" , Journal of Cleaner Production, vol. 41, pp114-125, 2013 